\title{
Distress calling induced by reductions in group size in ducklings reared with conspecifics or imprinting stimuli
}

\author{
STEPHEN J. GAIONI and LAURIE E. ROSS \\ Washington University, St. Louis, Missouri
}

\begin{abstract}
Peking ducklings were reared for 1-2 weeks with either 9 or 12 companions, which were either conspecifics or imprinting stimuli (blocks of foam rubber). They were then tested for their tendency to distress call as the number of companions was reduced systematically. Consistent with prior research, ducklings reared with conspecifics modulated their distress calling as a function of both the number of companions with which they were reared and the number of companions with which they were tested. In contrast, ducklings reared with moving imprinting stimuli gave few if any distress calls, regardless of the number of stimuli with which they were reared or tested, as long as at least one imprinting stimulus was present. The difference in responding did not reflect just a lack of attachment to the imprinting stimuli, since when all stimuli were removed these ducklings gave as many distress calls as the ducklings that had all their conspecifics removed. Finally, ducklings reared with stationary imprinting stimuli displayed an erratic pattern of distress calling when the number of test stimuli was manipulated. These latter ducklings appeared to be less strongly imprinted than the ducklings reared with either conspecifics or moving imprinting stimuli. Implications for understanding duckling perception of brood size and the nature of sibling vs. filial imprinting are examined.
\end{abstract}

Lorenz's (1935) pioneering work on the development of social attachments in young birds (imprinting) marked the beginning of an extensive research effort that continues to the present time. This research has focused largely on filial and sexual imprinting, that is, the processes by which a young bird learns the features of its mother and the species with which it will subsequently mate, respectively (Brosset, 1971; Hess, 1973; Hoffman \& Ratner, 1973; Immelmann, 1972; Schutz, 1965; Sluckin, 1965). Very little attention has been focused on sibling attachments (Shapiro, 1980). We have begun examining sibling interactions within the context of duckling perception of brood size (Gaioni, DePaulo, \& Hoffman, 1980; Gaioni, Hoffman, Klein, \& DePaulo, 1977). Ducklings reared in a brood of a given size adapt to that size such that they will give distress vocalizations if the number of birds in the brood is reduced substantially. Since mother ducks are insensitive to changes in the size of their brood, but are very sensitive to the distress calls of their young (Lorenz, 1935), this phenomenon may play an important role in keeping the brood intact. These distress vocalizations engendered by reductions in brood size show an orderly pattern: the greater the reduction in brood size, the more distress calls the re-

This research was supported by a Washington University Biomedical Research grant to Stephen J. Gaioni. Requests for reprints should be sent to Stephen J. Gaioni, Psychology Department, Washington University, St. Louis, Missouri 63130. maining birds will give (Gaioni et al., 1977). This sensitivity to changes in brood size does not depend on particular birds being present. A duckling reared in a brood of a certain size and then tested with an equal-sized brood composed of birds that are strangers will not give distress calls. Furthermore, increasing rather than reducing brood size has no effect on distress calling. These findings, based on laboratory investigations, are in complete agreement both with earlier naturalistic observations by Lorenz (1935) and with more recent quasi-naturalistic studies by Shapiro and his colleagues (Shapiro, 1980).

Although it is evident that ducklings are sensitive to brood size, nothing is presently known about the stimulus dimensions to which they are attending (e.g., visual, auditory, tactile). One approach to examining this issue is through the use of artificial stimuli as sibling surrogates. Such imprinting stimuli have proved to be of great value in elucidating the importance of various cues in filial imprinting (e.g., Hoffman \& Ratner, 1973). The utility of artificial stimuli stems from the control the experimenter gains over half of the interacting social dyad; the major disadvantage is that the young bird's response to such stimuli may provide a distorted view of its normal social behavior (Hess, 1973; Johnston \& Gottlieb, 1981). The resolution of this conflict is to use the artificial situation to disentangle a complex problem, but then to return to the natural environment to validate the laboratory results. The present research represents the beginning of such an approach. 


\section{EXPERIMENT 1}

Our research strategy was to demonstrate that ducklings reared with multiple imprinting stimuli (blocks of foam rubber) would respond to reductions in "brood" size in a manner analogous to the distress-call response of ducklings reared with multiple siblings when subjected to reductions in brood size. If so, it would then be possible to manipulate various stimulus dimensions (e.g., the spacing between the imprinting stimuli) and observe the effects of such manipulations on the ducklings' perception. Before such studies could be conducted, it was first necessary to solve a measurement problem. In our previous research, we tested ducklings reared in a large group by dividing the group into various-sized subgroups and then measuring the distress calls given by each subgroup (not each bird). If a duckling were reared with multiple imprinting stimuli and then was tested by the removal of various numbers of stimuli, we would be measuring the distress calls of a single bird. Since ducklings do not distress call independently of one another (Gaioni, 1982; Gaioni \& Platte, 1982), one cannot equate these two measures simply by dividing the number of calls given by a subgroup by the number of birds in that subgroup. A possible solution to this problem is to rear birds in large groups and then to test them individually by placing them with smaller-sized groups of companion birds. With this treatment, only the test bird would be expected to call, since adding a duckling to a group does not elicit distress calls from that group (see above). If ducklings tested in this fashion modulated their distress calling as a function of the number of other birds present, then we would subsequently be able to compare directly the response of ducklings to reductions in the number of conspecifics present with their responses to reductions in the number of imprinting stimuli present. Thus, in this first experiment, we simply used two treatment conditions: we tested for distress calling in ducklings reared in a large group, either by dividing the group into various-sized subgroups or by placing individual ducklings from the large group with various-sized groups of companion birds.

\section{Method}

Subjects. The subjects were 29 Peking ducklings (Anas platyrhynchos) hatched in the laboratory from eggs obtained from Heart of Missouri, Inc., Columbia, Missouri.

Apparatus. The ducklings were housed in $.6 \times .6 \times .6 \mathrm{~m}$ boxes constructed of Masonite, lined with a large plastic bag, and partially filled with an absorbent bedding material (San-i-cell).

The ducklings were tested in two boxes, identical to the home boxes, each located in a soundproof chamber. Suspended above each test box inside the chamber were a directionally sensitive microphone and a 25-W light. A one-way mirror was located in the top of each chamber, so that the experimenter could observe the ducklings without being seen.
The microphone was connected to a specially constructed fil ter that filtered out all sounds except for those in the frequency range in which distress calls occur $(3,000-4,000 \mathrm{~Hz})$. The timing of events was controlled by standard relay equipment, and data were recorded on Sodeco printout counters.

Procedure. Approximately $10-20 \mathrm{~h}$ after hatching, the ducklings were removed from the incubator and assigned to two experimental groups of 10 birds each, and companion groups of 4,3 , and 2 birds each. Assignment to the groups was random, with the constraint that each group have approximately equal proportions of early vs. late hatches. Until Day 10 posthatch, the birds remained undisturbed in their home boxes except for routine feeding and maintenance.

On Days 10-12 posthatch, both experimental groups received one test session each day. Immediately prior to testing, the birds in each of the groups had been marked with a marking pen so that they could be identified individually. For Group $10 \mathrm{~A}$, the test procedure involved placing the entire group in one of the test boxes, measuring the distress calls of the intact group for a 1-min baseline, then removing a given number of birds, placing them in the second test box, and measuring the distress calls in both boxes for a $1-\mathrm{min}$ period. All birds were then returned to the first test box for another 1-min baseline, and another separation was performed. These 1-min baselines and 1-min separation tests were repeated $n+1$ times, until all possible numbers of birds had been removed, ranging from 0 to $n$. The order of removals was determined randomly (e.g., 8 birds removed, followed by $0,5,4,3,1,9,2,7,6,10)$; the particular birds removed on any trial were also determined randomly. When " 0 " birds were removed from the group, the experimenter opened the test chamber and reached into the box for several seconds; when 10 birds were removed, the entire group was placed in the second test box. Twenty seconds were allotted between each 1-min measurement to allow the experimenter to carry birds from box to box. With this procedure, a single test session yielded two sets of $n+1$ removal measures, one set for each test box. Prior research (Gaioni et al., 1977) had revealed no differences between the distress calling of those birds moved to the second test box and the calling of the birds that remained in the first box.

The test procedure on these same days for Group 10B involved placing the entire group in one of the test boxes. The second test box contained companion birds: one of the companion groups of 4,3 , or 2 birds each, or one of the birds from the companion group of 2 birds, or all three companion groups combined ( 9 birds), or no birds. Thus, an experimental bird could be tested with $0,1,2,3,4$, or 9 companion birds. After the Group 10B birds were placed in the first test box for $1 \mathrm{~min}$, one of these birds was removed from this box and placed in the second box in which there were a given number of companion birds. Distress calls in the second box were recorded for $1 \mathrm{~min}$. The bird was then returned to its original group for a 1-min period, and then the same bird was placed back in the second test box with a different number of companion birds for $1 \mathrm{~min}$. This procedure was repeated until the bird had been tested with each of the possible number of companion birds. As in the test procedure for Group 10A, the particular sequence of companion group sizes was determined randomly (e.g., first 3 companion birds were present, then $0,4,2,9,1)$. Twenty seconds were allotted to carry the test bird from one box to the other between the 1 -min periods. Movement of the companion birds was carried out during the 1 -min periods in which the test bird was with its original rearing group. Each of the 10 birds in Group 10B was tested in this manner.

On Days 13-15 posthatch, Groups $10 \mathrm{~A}$ and 10B each received three more test sessions, but with the experimental procedures reversed.

During all the test sessions, experimenters observed the ducklings through the one-way mirrors on the tops of the test cham- 
bers. This was particularly important during the tests when companion birds were employed in order to ensure that only the experimental bird was giving distress calls. If the companion birds gave any distress calls, the trial was simply repeated following a 1-min period during which the test bird was with its experimental group.

Statistics. Analysis of the raw data from this and subsequent experiments revealed a high correlation between means and variances $(r=+.35$ to +.60$)$, and therefore a square root transformation $(\sqrt{X}+\sqrt{X+1})$ was performed on the data (Winer, 1971). For the larger test group sizes in each experiment (e.g., when a bird was tested with all 9 of its broodmates or with 9 companion birds), frequently the birds being tested gave no calls. Hence, because of singularity of variance, these trials were dropped from the analyses. Exclusion of these trials, when combined with the square root transformation, considerably reduced the correlation between means and variance in each experiment $(r=+.07$ to $+.17)$.

All statistical tests were two-tailed, with an $\alpha$-level set at .05 .

\section{Results and Discussion}

On only a few of the test trials in which companion birds were employed did these birds give any distress calls. When these trials were repeated, no distress calls were given by these birds.

It was not possible to make direct statistical comparisons across experimental treatments, since the unit of measurement differed in each case. For one treatment, the unit was the number of distress calls given by the subgroup tested, whereas, for the second treatment, the unit was the number of distress calls given by the individual test bird. It was possible, however, to compare the performance of the two groups when they received the same treatment.

For the condition in which the ducklings were tested by division of the group into two subgroups, a two-way analysis of variance was performed on the distress call data for subgroups of 1-7 birds, with factors for rearing group (10A vs. 10B) and subgroup size. For this analysis, each of the measures at a given subgroup size was considered to be an independent item. This analysis revealed a significant effect for subgroup size $[F(6,70)=23.84]$, but not for rearing group $[F(1,70)=.11]$ or for rearing group $X$ subgroup size $[F(6,70)=.55]$. Subsequent NewmanKeuls tests revealed significant differences in distress calling between the subgroups of $1,2,3$, or 4 birds; the larger subgroups did not significantly differ from one another. These data (Figure 1, left panel, collapsed across rearing groups) replicate Gaioni et al.'s (1977) finding that smaller subgroups of ducklings give more distress calls than larger subgroups.

For the treatment condition in which individual birds were tested with companion birds, each bird's distress calls were averaged for each companion group size across the three test sessions. A mixeddesign two-way analysis of variance computed on these data for 0-4 companion birds revealed a significant effect for companion group size $[F(4,72)=$ 153.64]. Neither the effect for rearing group $[F(1,18)$
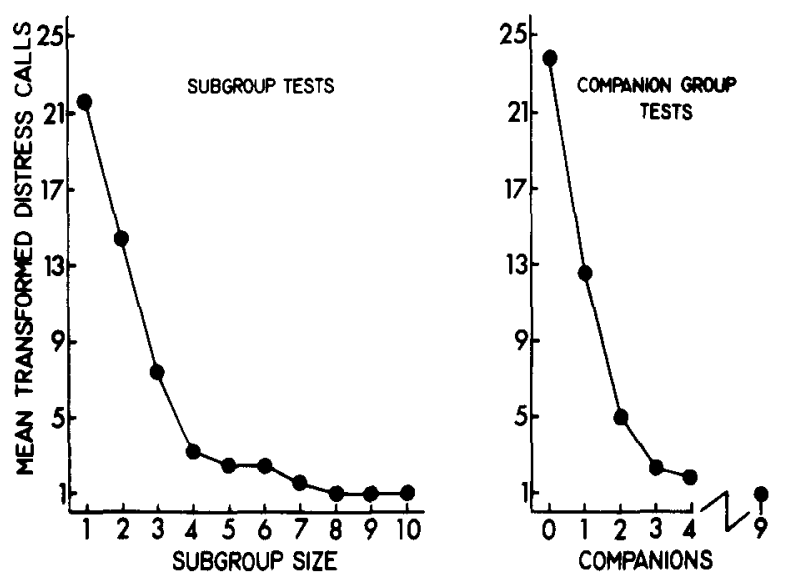

Figure 1. Mean transformed distress calls for ducklings from a large group tested in subgroups of various sizes (left panel) and for individual ducklings from a large group tested with various numbers of companion birds (right panel).

$=.30]$ nor the rearing group $\times$ companion group size interaction $[F(4,72)=.76]$ was significant. Subsequent Newman-Keuls tests revealed significant differences in distress calling between birds with $0,1,2$, or 3 companions present; there was no significant difference in distress calling between birds with 3 vs. 4 companions present. These data (Figure 1, right panel, collapsed across rearing groups) indicate that a single duckling placed with smaller numbers of companion birds gave more distress calls than it did when placed with larger numbers of companion birds.

It is clear that, for both treatment conditions, the ducklings showed an orderly pattern of distress vocalizations as a function of the number of birds with which they were tested. Under both conditions, the fewer the number of other birds present, the more distress calls the bird(s) gave. This closely replicates our previous research (Gaioni et al., 1977, 1980). The advantage of the companion-bird technique is that it allows the measurement of distress calling in individual ducklings. This makes it possible to compare directly the distress calling of ducklings reared with multiple conspecifics with that of ducklings reared with multiple imprinting stimuli (Experiments 2 and 3 ).

It is of interest to note that ducklings tested with other birds from their group appeared to alternate their distress calls. This was particularly striking during those trials in which there were only two birds together, since on those occasions there were usually large numbers of distress vocalizations. Typically, one bird would give a burst of distress calls, and as soon as it had stopped, the other bird would start. The birds seldom gave distress calls at the same time, but when this did occur it appeared that both birds would start calling at the same time and then one 
of the birds would quickly stop calling while the other bird continued. This alternation of response pattern has recently been documented more thoroughly (Gaioni, 1982; Gaioni \& Platte, 1982).

\section{EXPERIMENT 2}

In this experiment, ducklings in different treatment conditions were reared with either nine conspecifics or nine imprinting stimuli (foam rubber blocks). The ducklings were then tested for their distress call response to reductions in the number of companions present by being placed with various numbers of either companion birds or foam rubber blocks. Based on the previous experiment, it was expected that the ducklings reared and tested with conspecifics would modulate their distress calling as a function of companion group size. The question of primary interest was whether ducklings reared and tested with the foam rubber blocks would exhibit a similar response pattern. If they did, then it would subsequently be possible to manipulate features of the imprinting stimulus array systematically in order to determine the cues critical for duckling perception of brood size. As a further issue, we examined whether movement of the imprinting stimuli might have a critical effect on the ducklings' response to these stimuli. Research on filial imprinting has suggested that movement may be important for imprinting to occur, either because it serves as an innate elicitor of filial behavior (Hoffman \& Ratner, 1973) or because it makes the imprinting stimulus more salient (Bateson, 1964; Eiserer, 1980).

\section{Method}

Subjects. The subjects were 36 Peking ducklings.

Apparatus. The housing and test boxes were identical to those used in Experiment 1. The imprinting stimuli were foam rubber cubes measuring $7.6 \mathrm{~cm}$ on each edge. Each cube was suspended a few centimeters above the floor of the housing box by means of a wire rod that was attached at one end to the cube and at the other end to an overhead wire frame. The cubes were arranged in a $3 \times 3$ array measuring approximately $46 \times 46 \mathrm{~cm}$. For one treatment condition, the cubes were kept stationary by supporting wires soldered to the frame; in a second condition, the wires were hooked over the frame such that the cubes could swing freely. For this latter condition, a fishing line also attached the frame to a motor which caused these frames (and hence the blocks) to sway back and forth over a distance of several centimeters for approximately $6 \mathrm{~h}$ each day, in $1.5 \mathrm{-h}$ units, between $8 \mathrm{a} . \mathrm{m}$. and $6 \mathrm{p} . \mathrm{m}$.

When the ducklings were tested using the foam rubber blocks (see below), a frame similar to that described above was attached to the test box so that blocks could be hung in a $3 \times 3$ array identical to those found in the housing boxes. These blocks were hung in such a manner as to make it easy to remove individual blocks from the array during the course of testing.

Procedure. The ducklings were hatched in the laboratory incubator in visual isolation from one another. Approximately 10-20 h after hatching, the ducklings were removed from the incubator and assigned randomly to various experimental conditions with the constraint that each condition had approximately equal pro- portions of early vs. late hatches. Ten birds were housed together (conspecific condition), and 17 birds were housed individually in boxes which each contained nine imprinting stimuli. Of these latter birds, 9 were exposed to the moving imprinting stimuli (MIS condition), and 8 were exposed to the stationary imprinting stimuli (SIS condition). One of the SIS birds died prior to testing, reducing this group to 7 ducklings. The 9 remaining birds were housed in groups of 2,3 , and 4 birds each. These birds served as test companions when the conspecificcondition birds were tested. All of the birds in each condition were marked on their backs with a marking pen so that they could be individually identified.

On Days 1-3 posthatch, the ducklings were undisturbed in their home boxes except for routine maintenance. On each of Days 4-6 posthatch, all ducklings were given 20 -min habituation sessions to the test box. Each duckling in the MIS and SIS conditions was placed individually in the test box, in which was suspended an array of nine imprinting stimuli identical to those found in their home boxes. Each of the conspecific-condition birds was also habituated to the test situation by being placed individually in the test box with all nine test companion birds. Thus, the birds in all three experimental conditions were exposed to the same number of "companions" in the test box as were present in their housing boxes.

On Days 7-8 posthatch, testing was conducted. At the start of each test for the MIS and SIS birds, a duckling was placed in the test box with the full array of nine imprinting stimuli present. The bird was then given a series of $101-$ min test periods, during which each possible number of imprinting stimuli from 0 to 9 was removed and the bird's distress calling was measured. As in the previous experiment, the order of removals was randomized (e.g., 8 blocks removed, then $0,5,4,3,1,9,2,7,6$, 10 ), and the particular blocks to be removed on a given test were determined randomly. The same random sequences were employed for each bird, but the random sequences were changed between test days. Each 1-min test was preceded by a 1-min baseline in which all nine blocks were present in the test box. The blocks were removed from or returned to the test box during the $30 \mathrm{sec}$ which separated the baseline and test periods; no distress calls were recorded during that time.

The birds in the conspecific condition were tested by being placed individually in the test box with all nine companion birds. In a procedure similar to that of the MIS and SIS tests, the bird was then subjected to a series of $101-$ min tests during which each possible number of companion birds, from 0 to 9 , was removed. The particular companion ducklings removed depended on the size of the group in which these companions had been reared. For example, if a duckling was to be tested with six companions, the groups of four and two companion birds remained with the test duckling, and the group of three was removed. When a duckling was tested with one companion, one of the birds from the group of two was left in the test box. As demonstrated in the previous experiment, this procedure allowed us to measure distress calls from the test duckling alone, since the companion birds were accustomed to living in smaller groups and hence were not expected to distress call when other companion birds were removed. To ensure that this was the case, the experimenter observed the birds through the one-way mirror throughout testing. In a manner similar to that of the MIS and SIS tests, each test period was preceded by a 1 -min baseline in which all nine companion birds were present in the test box, and the $30 \mathrm{sec}$ between the baseline and test periods were used to remove and return companion birds.

\section{Results and Discussion}

Both the MIS and conspecific-condition birds gave high levels of distress calls when all companions were removed, but gave few, if any, calls when more than one (MIS condition) or two (conspecific con- 


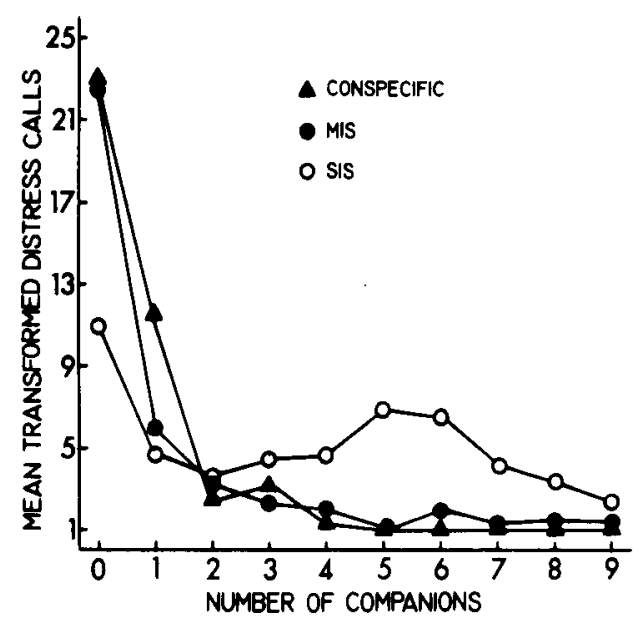

Figure 2. Mean transformed distress calls for ducklings reared with uine conspecifics, moving imprinting stimuli, or stationary imprinting stimuli, and then tested with various numbers of these companions present.

dition) companions were present (Figure 2). In contrast, the SIS birds did not show any systematic relationship between number of companions and amount of distress calling. A two-way analysis of variance performed on the test data for the three conditions for 0-7 companions present showed a significant effect for number of companions present $[F(7,161)=85.60]$ and a significant interaction between groups and number of companions present $[F(14,161)=8.98]$. Further analyses revealed that the difference between the MIS and conspecific birds fell short of statistical significance $[F(7,161)=2.08$, $.10>\mathrm{p}>.05$ ], but that the birds in each of these conditions differed significantly from the SIS birds $[\mathrm{Fs}(7,161) \geqslant 4.07]$.

Informal observation of the MIS and SIS birds suggested that the former were much more strongly attached to the imprinting stimuli. When blocks were returned to the test box following a test period, these birds would often utter cheeps of contentment (Collias, 1962). Furthermore, during the test sessions they would typically nestle in contact with one of the blocks, a behavior that was most impressive during the tests in which only one or two blocks were present, as it was clear that the birds were actively seeking contact with the blocks rather than merely contacting them by chance. This behavior was similar to that evidenced by conspecific birds tested with other ducklings as companions. The SIS birds, in contrast, often crouched in a corner of the test box throughout testing, and showed no apparent response to the return of blocks to the test box following a period of absence.

In summary, the ducklings in both the MIS and conspecific conditions behaved quite similarly by ap- pearing to be strongly attached to the social companions with which they had been reared. The small difference in distress calling between these two groups fell short of statistical significance. In contrast, the SIS birds appeared to be much less strongly attached and behaved in a more erratic fashion. This latter result is consistent with research suggesting that visual movement facilitates strong imprinting (e.g., Eiserer, 1980; Hoffman \& Ratner, 1973).

\section{EXPERIMENT 3}

One problem with interpreting the results of Experi. ment 2 is that the ducklings in neither the conspecific condition nor the MIS condition gave very many distress calls even when only a single companion was placed in the test box. Thus, there was little opportunity to observe possible differences between these treatment conditions. Since our previous research (Gaioni et al., 1977) had shown that increasing the size of the group with which a duckling is reared would result in a higher level of distress calling during testing with a small number of companions, we believed that, if differences existed in ducklings' responses to multiple conspecifics vs. multiple imprinting stimuli, such a manipulation should increase the chances of observing these differences. Accordingly, in Experiment 3 the number of companions with which a bird was reared was increased to 12 . Furthermore, the SIS condition was eliminated.

\section{Method}

Subjects. The subjects were 37 Peking ducklings.

Apparatus. The apparatus was identical to that described in the previous experiment, except that the 12 foam rubber blocks were arranged in a $4 \times 3$ array hung from the $46-\mathrm{cm}^{2}$ frame, and two test boxes were employed.

Procedure. The hatching and habituation procedures were identical to those used in the previous experiment. Testing occurred on Days 7 and 8 posthatch, and was identical to that conducted in the previous experiment except for two minor modifications. First, rather than testing each bird with every possible number of companions, from 0 to 12 , tests were performed only with 0 to 5 and 12 companions present. Based on the previous experiments, it was expected that the ducklings would give very few, if any, distress calls when the number of companions present exceeded half of the original rearing group size. The test involving the presence of all 12 companions served as a check on this expectation. Second, rather than keeping the test duckling in a single test box for both the baseline and test periods, the duckling was kept in one test box during all 1-min baseline periods and then moved to the second test box for all 1 -min test periods. This procedure, which was different from that employed in Experiment 2 but similar to the procedure employed in Experiment 1, made it easier to change the size of the companion group to be used during the succeeding 1-min test period with minimal disturbance of the test duckling. During the baseline periods, the ducklings in the conspecific condition were kept with their entire home rearing group, whereas the ducklings in the MIS condition were kept with a full $4 \times 3$ array of foam rubber blocks. 


\section{Results and Discussion}

Both ducklings reared with conspecifics and those reared with multiple imprinting stimuli gave large and approximately equal numbers of distress calls when tested with no companions present (Figure 3). This suggests that the ducklings in both conditions were strongly attached to their social companions. When one or more companions were present, however, the birds in these two conditions behaved differently. The ducklings in the MIS condition virtually ceased calling as soon as a single imprinting stimulus was added, whereas the ducklings in the conspecific condition required three or four companions before they reduced calling by a similar amount. These results were verified by an analysis of variance computed on the data from trials when 0-5 companions were present. Significant effects were found for number of companions remaining $[F(5,105)$ $=128.7$ ] and, more importantly, for experimental condition $[F(1,21)=25.42]$ and the number of companions $x$ experimental interaction $[F(5,105)=$ 14.20]. F tests for simple effects revealed significant differences between the conditions on trials with one or two companions present $[\mathrm{Fs}(1,21) \geqslant 12.93]$. These results indicate that ducklings do not treat multiple conspecifics and multiple imprinting stimuli in an identical fashion. The addition of a single imprinting stimulus appears to have the same suppressive effect as the addition of several conspecifics. Interestingly, this parallels recent findings from our laboratory (Gaioni et al., 1980) involving a procedure in which ducklings were exposed as a large group to a single imprinting stimulus. Those studies also revealed that a single imprinting stimulus was equivalent to several ducklings in terms of its effectiveness in suppressing distress calls.

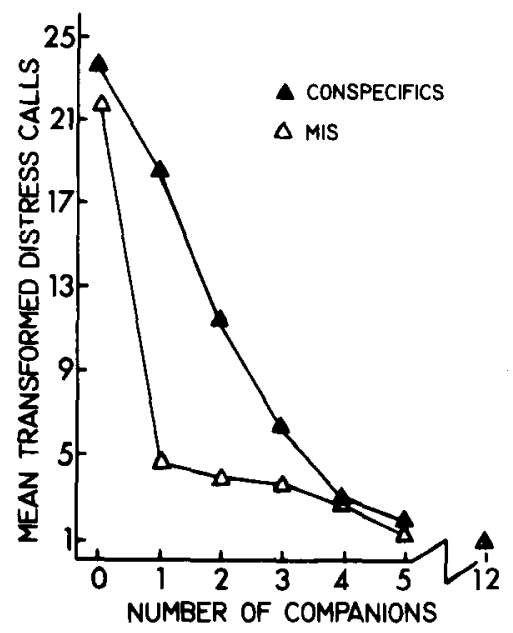

Figure 3. Mean transformed distress calls for ducklings reared with 12 conspecifics or 12 moving imprinting stimuli, and then tested with various numbers of these companions present.
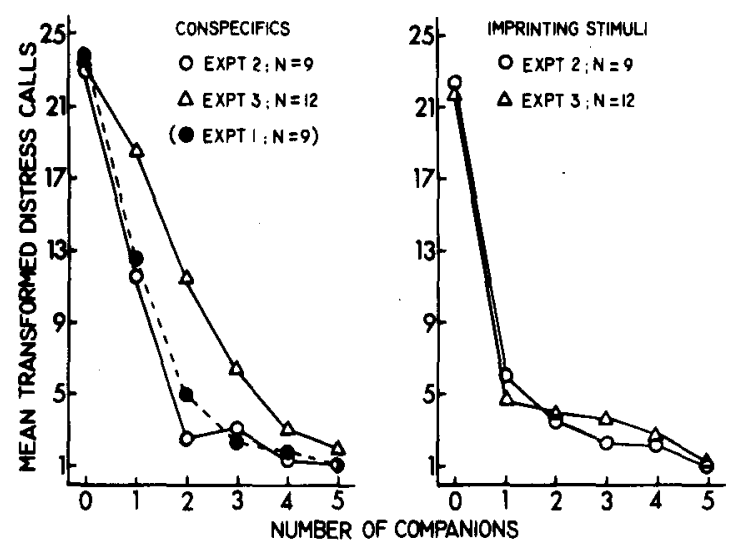

Figure 4. Mean transformed distress calls for ducklings reared either with conspecifics (left panel) or with moving imprinting stimuli (right panel), as a function of both the number of companions present during rearing $(9$ vs. 12) and the number of companions present during testing. In the left panel, the data from the companion group tests of Experiment 1 are included to allow comparison with the data from Experiments 2 and 3 . See text for further details.

A further difference in the response of ducklings to multiple conspecifics vs. multiple imprinting stimuli concerns the effect of the size of the home rearing group ( 9 vs. 12 companions) on subsequent distress calling. This effect can be seen in Figure 4, which combines the results of Experiments 2 and 3. A threeway mixed-model analysis of variance with repeated measures revealed a significant triple interaction among experimental condition (MIS vs. conspecific), number of companions during testing (0-5), and number of companions during rearing (9 vs. 12) (see Table 1). Subsequent simple two-way interaction $F$ tests, in which distress calls were examined as a function of the number of companions present during testing and rearing, revealed a significant interaction for the conspecific-condition birds $[F(5,95)=$ 5.69] (see Figure 4, left panel), but not for the MIScondition birds $[F(5,85)=.60]$ (see Figure 4 , right panel). This indicates that the test responding of the birds reared with other ducklings depended on the number of companions in their rearing group, but this was not the case for the birds reared with imprinting stimuli. Thus, birds reared with 12 other ducklings required the presence of more conspecifics to suppress their distress calling during testing than did birds reared with 9 other ducklings. Birds reared with imprinting stimuli, however, showed no such differential responding; for each group size, a single stimulus was sufficient to inhibit virtually all distress calling behavior.

Although these latter results should be interpreted with caution, both because the birds were drawn from two separate hatches and because of minor procedural differences between Experiments 2 and 3 , several factors support their validity. First, the 
Table 1

ANOVA Performed on the Transformed Distress Calls With Factors for Type of Companion (Conspecifics vs. Imprinting Stimuli), Size of Rearing Group ( 9 vs. 12), and Number of Test Companions (0-5)

\begin{tabular}{lrrr}
\hline \multicolumn{1}{c}{ Source } & $\mathrm{df}$ & $\mathrm{MS}$ & $\mathrm{F}<$ \\
\hline Total & 251 & & \\
Between Subjects & 41 & & \\
$\quad$ Companion Type & 1 & 550.09 & 21.45 \\
Rearing Group & 1 & 293.29 & 11.43 \\
Companion Type X Rearing Group & 1 & 165.65 & .001 \\
Subjects Within Groups [Error (Between)] & 38 & 25.65 & .005 \\
Within Subjects & 210 & & \\
Test Number & 5 & 2707.93 & 274.36 \\
Companion Type X Test Number & 5 & 153.96 & 15.60 \\
Rearing Group X Test Number & 5 & 41.20 & .001 \\
Companion Type X Rearing Group X Test Number & 5 & 29.96 & .001 \\
Test Number X Subjects Within Groups [Error (Within)] & 190 & 9.87 & 3.04 \\
\end{tabular}

results for the conspecific-condition ducklings replicate previous research from our laboratory (Gaioni et al., 1977). Second, the birds in Experiment 1 were reared in groups that were the same size as those in which the conspecific birds of Experiment 2 were reared, but they were tested with virtually the same procedure as that used in Experiment 3. As the left panel of Figure 4 reveals, these ducklings showed the same pattern of responding as did the ducklings of Experiment 2, suggesting that the procedural and hatch differences were of little, or no, importance. Third, Experiments 2 and 3 were conducted by the same experimenter, using the same equipment and utilizing successive hatches less than a month apart.

\section{GENERAL DISCUSSION}

We began this series of experiments anticipating that ducklings would respond to multiple imprinting stimuli in a fashion similar to that in which they responded to multiple siblings; we ended with the discovery of potentially important differences in their responses to multiple imprinting stimuli vs. siblings. Ducklings reared with a group of conspecifics and then subjected to reductions in group size modulated their distress calling as a function of both the number of birds with which they were reared and the number of birds with which they were tested. Both of these effects have been previously reported from our laboratory (Gaioni et al., 1977). In contrast, ducklings reared with multiple moving imprinting stimuli and then subjected to reductions in "group" size showed little distress calling, regardless of their rearing or testing group size, as long as a single imprinting stimulus was present. This difference cannot be ascribed merely to the ducklings' lack of attachment to the imprinting stimuli. When ducklings were tested with no companions present, those reared with imprinting stimuli gave as many distress calls as those reared with conspecifics. Furthermore, informal observations revealed that the test ducklings responded to the return of conspecifics and imprinting stimuli in a very similar fashion: running to the returning companions, cheeping contentedly, and nestling in physical contact with them. In contrast to both of these conditions, ducklings reared with stationary imprinting stimuli appeared, both on the basis of the distress call data and on the basis of informal observations, to be less strongly attached to these stimuli. This difference in strength of imprinting is consistent both with Hoffman and Ratner's (1973) view that visual movement is a critical component of the learning process by which filial attachments develop and with Bateson's (1964) and Eiserer's (1980) view that visual movement serves to make the imprinting stimulus more conspicuous, hence resulting in stronger imprinting.

There is a variety of possible explanations for the difference in distress calling between the ducklings reared with conspecifics and those reared with moving imprinting stimuli. Perhaps the array of imprinting stimuli lacked some biologically relevant feature critical for duckling perception of brood size. One might examine differences in the features of the imprinting stimuli and in those of the conspecifics for clues to the features necessary for such perception. For example, ducklings in a brood often cluster in close contact with one another (Lorenz, 1935; Shapiro, 1980; personal observations). This is probably due both to the warmth provided by physical contact and to the development of strong mutual attachments. In contrast, the imprinting stimuli were spread out in a fixed array, and hence a duckling could never huddle in contact with more than one or two blocks. Perhaps perception of brood size is based on ducklings' learning the size of this cluster. This hypothesis might be tested by manipulating the spacing between imprinting stimuli in an array while holding constant the number of stimuli present. Al- 
ternatively, one might rear groups of ducklings in housing units in which the spacing between ducklings could be controlled. For example, if small broods were separated from one another by glass barriers, would the individual birds behave as if they had been reared in large or small broods when subsequently tested for separation-induced distress calling?

Perhaps the most theoretically interesting account of the observed differences in ducklings' responding following rearing with multiple imprinting stimuli vs. multiple conspecifics is derived from Lorenz's (1935) view of filial vs. sibling imprinting. Lorenz argued that whereas a wide variety of stimuli have the potential to serve as effective mother surrogates for the elicitation of filial behaviors in young ducklings, the sibling schema is much more innately determined, such that only a conspecific has the potential to elicit sibling behaviors. This is why, according to Lorenz (1935), a young duckling would accept a hen of another species, or even himself, as a maternal companion, but would not accept chicks of another species as sibling companions. If this analysis is correct, then the ducklings in the present experiments may have responded differently to siblings vs. imprinting stimuli because the latter were treated by the ducklings as mother surrogates rather than as sibling surrogates. Since the ducklings have evolved in an environment in which multiple siblings, but only one mother, commonly are present, it might be expected that ducklings would not be sensitive to multiple imprinting stimuli. Unfortunately, there is little evidence to support Lorenz's view. Indeed, those comparisons that can be made between filial and sibling imprinting suggest little or no difference between the two. Both are characterized by a relatively brief sensitive period during the first few days after hatching (Hess, 1973; Lorenz, 1935; Ramsey \& Hess, 1954). If a young bird is socially isolated during this period, then the bird will typically flee and give distress calls when either a sibling or an imprinting stimulus is presented, rather than following and giving calls of contentment (Hoffman, Ratner, Eiserer, \& Grossman, 1974). Furthermore, ducklings will learn an operant response to gain access to either a sibling or an imprinting stimulus (Bateson \& Reese, 1969; Gaioni, Hoffman, DePaulo, \& Stratton, 1978; Peterson, 1960), and in both cases the pattern of responding is quite similar, with responses occurring in bursts, rather than at a steady rate (Gaioni et al., 1978; Hoffman \& Kozma, 1967). Thus, while much more needs to be known about sibling imprinting, an important process which has received little investigation (Shapiro, 1980; Storey \& Shapiro, 1979 ), there is presently no evidence to support the contention that our results can be explained in terms of differences between filial and sibling imprinting. This, in turn, raises a final and related issue. Inves- tigators employing an imprinting stimulus commonly assume that this stimulus is serving as a mother surrogate (e.g., Hess, 1973; Hinde, 1974; Hoffman \& Ratner, 1973; Sluckin, 1965; Sluckin \& Salzen, 1961). The present research, however, emphasizes the need to critically examine the relationship between imprinting stimuli and natural social companions in a young bird's environment-mother, siblings, potential mate, or whatever.

\section{REFERENCES}

Bateson, P. P. G. Relation between conspicuousness of stimuli and their effectiveness in the imprinting situation. Journal of Comparative and Physiological Psychology, 1964, 58, $407-411$.

Bateson, P. P. G., \& Reese, E. P. The reinforcing properties of conspicuous stimuli in the imprinting situation. Animal Behaviour, 1969, 17, 692-697.

Brosset, A. L' "imprinting," chez les Colombides-étude des modifications comportementales au cours de vieillisement. Zeitschrift für Tierpsychologie, 1971, 29, 279-300.

Collias, N. E. The behaviour of ducks. In E. S. E. Hafez (Ed.), The behaviour of domestic animals. London: Balliere, Tindall, \& Cox, 1962.

Eiserer, L. A. Development of filial attachment to static visual features of an imprinting object. Animal Learning \& Behavior, 1980, 8, 159-166.

Galonı, S. J. Distress call alternation in Peking ducklings (Anas platyrhynchos). Animal Behaviour, 1982, 30, 774-789.

Gaioni, S. J., DePaulo, P., \& Hoffman, H. S. Effects of group rearing on the control exerted by an imprinting stimulus. Animal Learning \& Behavior, 1980, 8, 673-678.

Gaioni, S. J., Hoffman, H. S., DePaulo, P., \& Stratton, V. Filial reactions in older ducklings: Some tests of the reinforcement theory of imprinting. Animal Learning \& Behavior, 1978, 6, 19-26.

Gaioni, S. J., Hofrman, H. S., KLein, S. H., \& DePaulo, P. Distress calling as a function of group size in newly hatched ducklings. Journal of Experimental Psychology: Animal Behavior Processes, 1977, 3, 335-342.

Gatoni, S. J., \& Platre, P. L. Sibling interactions in mallard ducklings (Anas platyrhynchos). Behaviour Analysis Letters, 1982, 2, 189-196.

Hess, E. H. Imprinting: Early experience and the developmental psychobiology of attachment. New York: Van Nostrand Reinhold, 1973.

Hinde, R. A. Biological bases of human social behaviour. New York: McGraw-Hill, 1974.

Hoffman, H. S., \& Kozma, F., JR. Behavioral control by an imprinted stimulus: Long-term effects. Journal of the Experimental Analysis of Behavior, 1967, 10, 495-501.

Hoffman, H. S., \& Ratner, A. M. A reinforcement model of imprinting: Implications for socialization in monkeys and men. Psychological Review, 1973, 80, 527-544.

Hofrman, H. S., Ratner, A. M., Eiserer, L. A., \& Grossman, D. J. Aggressive behavior in immature ducklings. Journal of Comparative and Physiological Psychology, 1974, 86, 569-580.

ImMELMANN, $K$. Sexual and other long-term aspects of imprinting in birds and other species. Advances in the Study of Behavior, 1972, 4, 147-174.

Johnston, J. D., \& Gotrtieb, G. Development of visual species identification in ducklings: What is the role of imprinting? Animal Behaviour, 1981, 29, 1082-1099.

Lorenz, K. Z. Companions as factors in the bird's development. In K. Lorenz (Ed.; R. Martin, trans.), Studies in animal and human behavior (Vol. 1). Cambridge, Mass: Harvard Uni- 
versity Press, 1970. (From Zeitschrift fur Ornithologie, 1935, 83, 137-213; 289-413.)

Peterson, N. Control of behavior by presentation of an imprinting stimulus. Science, 1960, 132, 1395-1396.

RAmseY, A. O., \& Hess, E. H. A laboratory approach to the ștudy of imprinting. Wilson Bulletin, 1954, 66, 196-206.

Schutz, F. Sexuelle Pragung bei Anatiden. Zeitschrift fur Tierpsychologie, 1965, 22, 50-103.

Shapino, L. J. Species identification in birds: A review and synthesis. In A. Roy (Ed.), Species identity and attachment. New York: Garland Press, 1980.

SuUcKIN, W. Imprinting and early learning. Chicago: Aldine, 1965.
Sluckin, W., \& Salzen, E. A. Imprinting and perceptual learning. Quarterly Journal of Experimental Psychology, 1961, 13, 65-77.

Storey, A. E., \& Shapino, L. J. Development of preferences in white Peking ducklings for stimuli in the natural post hatch environment. Animal Behaviour, 1979, 27, 411-416.

WINER, B. J. Statistical principles in experimental design. New York: McGraw-Hill, 1971.

(Manuscript received February 25, 1982; revision accepted for publication August 2, 1982.) 